DE DE GRUYTER OPEN
Journal of Intercultural Management

Vol. 5, No. 4, December 2013, pp. 49-64

DOI 10.2478/joim-2013-0026

Michał Chmielecki

University of Social Sciences

Marcin Lisowski

University of Social Sciences

\title{
The use of social media in Public Relations in Poland and the United Kingdom - case studies from automotive industry
}

\begin{abstract}
Current changes in technology and the role of the Internet open up new opportunities for companies both to communicate with the public and organisational functionality of its own structure. The fact that Social Media entered the business landscape, can be globally experience in the novel ways of communication, particularly between all stakeholders in organisation's environment, but also in growing tendency in search for the new knowledge and expertise in digital environment. Organisations existing in brick-and-mortar landscape, observing ongoing and continues development of the digital technologies that ubiquitously transforming the way we perceive a role of marketing and making Public Relations more fascinating discipline in the XXI century. Becoming more exposed to the public, marketers needs to understand importance of their role in the new age of digital era but more importantly to be able to adapt to a new environment by building their digital presence with accordance to tomorrow's reality and prevailing expectations. Every geographical region has its own unique approach in practicing public relations and building their own understanding of that concept. What is more, one also has to take into consideration the relations between corporate culture and organizational environment and it's influence on certain managerial practices.

Broadening the traditional perspective and communication by the new and growing acceptance of the dot.com era, internet is defining new rules, that continuously supported by the visionary and innovatory approach of modern organisations, not only modelling PR and marketing but companies as a whole. The aim of this article is to identify the changing trends of the new PR model that continuously evolve in the digital era and changing our way of building robust two-direction communication channel.
\end{abstract}


The article presents four case studies (Poland and the UK) of social media in PR on the automotive market.

Key words: Public Relations, social media, Poland, UK, automotive industry, car manufacturers

\section{Introduction}

Public relations is more important than it used to be, mainly because of the prevailing perception that the world today is more media-driven than before. This new approach, is more visible in driving organisations towards more transparent and explicit utilisation of available communication channel, that on the other hand paradoxically creates a peculiar phenomena - customer's indifference. Audience feeling more overloaded with the media context and becoming reluctant to the new messages, that on the other side are strongly and more frequently broadcasted by the companies to build their brand position by selective utilisation of available communication medium. Therefore, in the era of ubiquities almost access to internet, it is not surprisingly that current transition of the media stream will have an ultimate impact on the way we communicate, and may forevermore alter the meaning of Public Relations and its role in the new age.

In the era where more individuals embracing the digital technology trends, every broadcasted information travels in a speed of light. Within seconds a press release originating in New York is read by thousands of people on their computer, mobile or PDA screens in China, Mexico, Norway, Poland etc. PR is experiencing a dramatic paradigm shift in the way we communicate, organise and perceive the information translated through bits channel in the e-world .

This shift caused by mainstream of Internet acceptance and globalisation, was effectively embraced by commonly known entities like Google, Facebook, MySpace, Twitter that have outgrown the vision of Marshall McLuhan's [McLuhan, 1965] global village and with it unprecedented expectations of public relations practitioners to service a new, intercultural, worldwide audience [Fitzgerald, Spagnolia, 1999, Compare Granys, Grandys, 2011].

The explosive growth of Internet and active participation in the process of many organisations, has initiated the embark of Web2.0 revolution, that harness the distributed and collaborative potential of the internet in the new way of connecting people around the globe, regardless of their origin. The new technology empowered customers in the way unseen before. With the media rich content, customers is in the position where they decides and controls the flow of the information in the way that suits them most, deciding when, where and how they wants particular message to be accepted. Being connected through the internet medium with virtually whole world, it encourage them to create their own content and disseminate by means of the same channel 
as any organisation, concurrently influencing audience through peer-topeer connection. We embarked in the era of Social Media, era in which new communication platform leverage customers presence in dot.com world and offers them tools to connect with every organisation in increasingly divert and relevant way.

\section{Public relations}

Public relations play an important role in the world of international business. From a corporate standpoint, effective PR campaign enables companies to develop positive images for their businesses. From the marketing perspective, public relations also plays an important role as part of the overall marketing strategy offering numerous tools to position the company's product or brand on the market and build brand equity.

The formal practice of "public relations" dates to the early 20th century. In the relatively brief period leading up to today, public relations has been defined in many different ways. The definition often evolving alongside with public relations' changing roles and technological advances. The earliest definitions emphasized press agentry and publicity, while more modern definitions incorporate the concepts of "engagement" and "relationship building."

Public relations has developed very rapidly in recent years, partly because management of various commercial and non-commercial organizations have discovered a need for public relations activities. There has also been a considerable increase in the means by which public relations messages can be conveyed.

In 2011/12, PRSA led an international effort to modernize the definition of public relations and replace a definition adopted in 1982. PRSA initiated a crowd-sourcing campaign and public vote that produced the following definition: "Public relations is a strategic communication process that builds mutually beneficial relationships between organizations and their publics." This definition focuses on the basic concept of public relations - as a communication process, one that is strategic in nature and emphasizing "mutually beneficial relationships." http://www.prsa.org/aboutprsa/ publicrelationsdefined/ 30.07.2012].

As a management function, public relations also encompasses the following [http://www.prsa.org/aboutprsa/publicrelationsdefined/ 30.07.2012]:

- Anticipating, analyzing and interpreting public opinion, attitudes and issues that might impact, for good or ill, the operations and plans of the organization.

- Counselling management at all levels in the organization with regard to policy decisions, courses of action and communication, taking into account their public ramifications and the organization's social or citizenship responsibilities. 
- Researching, conducting and evaluating, on a continuing basis, programs of action and communication to achieve the informed public understanding necessary to the success of an organization's aims. These may include marketing; financial; fund raising; employee, community or government relations; and other programs.

- Planning and implementing the organization's efforts to influence or change public policy. Setting objectives, planning, budgeting, recruiting and training staff, developing facilities - in short, managing the resources needed to perform all of the above.

We see traditional PR as a means of creating a mutual and collaborative platform, based on which we can build strong and long-lasting communication with all stakeholders. In the traditional approach, however, PR people were limited to certain channels, where they needed to relay on mainstream media that were mainly supporting large companies with high budgets projects or global initiatives. The exclusivity of the communication through the media stream in that respect, confined some organisations from experiencing the coverage of their press release, and opportunity to convey information and exposure of their new product or innovative service. With growing importance of the media role in building the company's presence on the market place, the relationship with PR organisations was even more critical for their further existence. Therefore prior to 1995 there was no significant option for company to benefits from the existing main stream channels and to be able to tell the story to the world, without large money investment and further financial support. Hence, it is not surprisingly that the new paradigm shift was only a matter of time:

Old Rules of PR [Meerman 2011, p. 11]

- Media was the only way to get airtime

- Organisations had to communicate with journalists via press release

- Organisations had to provide significant news if they wanted to be allowed to write press release

- Limited access to the news content for the buyer

- PR and Marketing were separate disciplines

\section{Social media and Social Networking Sites}

Our economic and culture slowly shifting away from the mainstream markets and moving toward the broad number of niche products that are becoming more available through the existing channels. It is mainly experience due to new era of the prevailing existence of electronic platform, minimised constraints of the physical shelf and improvements of the distribution and cost optimisation. New economical model, described by Chris Anderson as 
'Long Tail' [Anderson, 2009, pp. 53-54] is changing our current economical landscape that evolves fundamentally by growing acceptance of new medium, Internet. In this dispersed market, Social Media plays vital role.

Social media is a relatively new concept, therefore we continuously see evolution of its definition and ongoing efforts to capture the essence of the new medium as an universally accepted terminology. Even though it may sound impossible to achieve, reviewing existing literature we can explore the main frame of the new concept to straighten our understanding and knowledge in this area.

Figure. 1. Social media development from 1995 to 2008

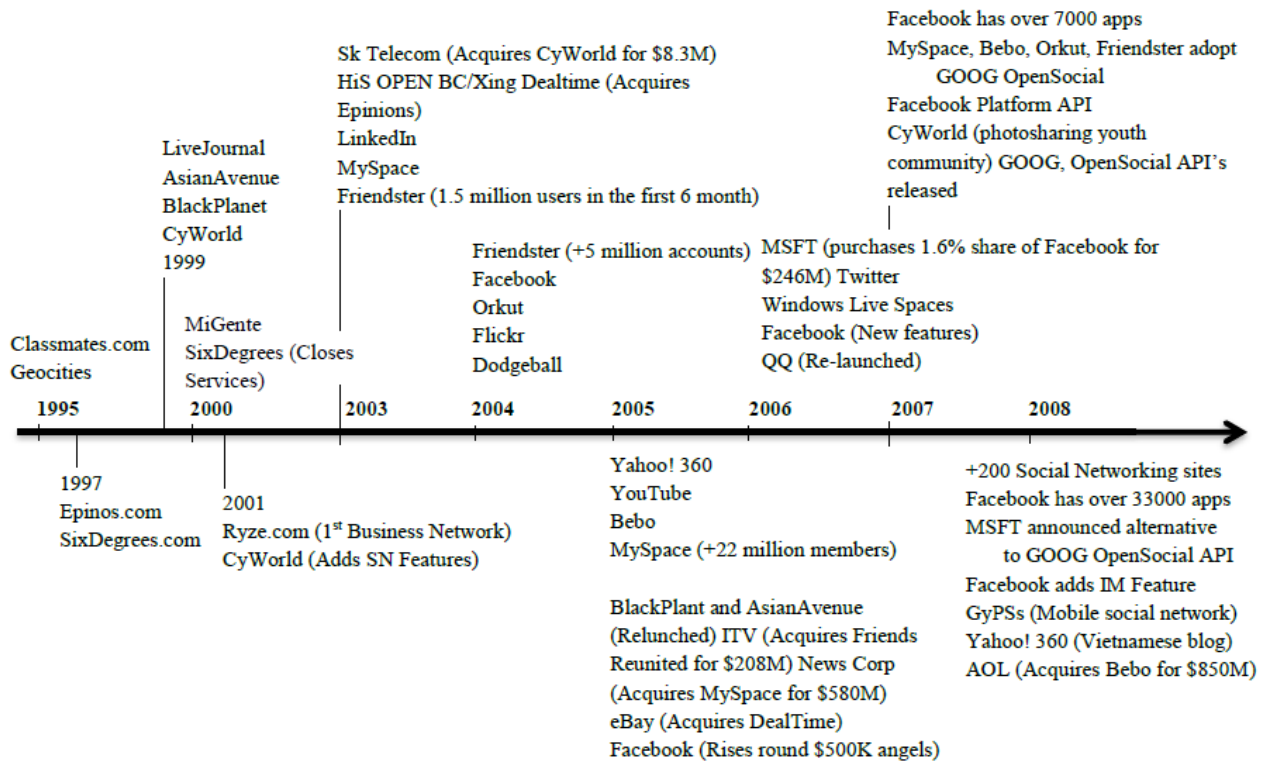

Source: Trebnick [2008]

Safko and Brake [2009, p.6] observed that social media "refers to activities, practices, and behaviours among communities of people who gather online to share information, knowledge, and opinions using conversational media". Weinberg [2009, p.1] notes that social media "relates to the sharing of information, experiences, and perspectives throughout community-oriented websites". Comm [2009] believes that social media is content that has been created by its audience. The Universal McCann report refers to social media as "online applications, platforms and media which aim to facilitate interaction, collaboration, and the sharing of content"[Universal Mccann, 2009 p.10]. David Merman Scott adds that emphasising that Social Media differ from mainstream 
media in that' anyone can create, comments and add to the content' by different from of text, audio, video or community [Meerman 2011, p.38]. This extension to the original, articulated by many authors definition objectivise on 'sharing and garnering' information, by including the important ownership role of the content to virtually 'anyone', makes Social Media a powerful tool.

Palmer and Koenig-Lewis [2009, p.162] divide social media into following categories:

- blogs,

- social networks,

- content communities,

- forums/bulletin boards,

- content aggregators.

Zarrella offers a basic definition that offers another inside to the term, looking at the concept through the prism of the technology According to him social media consists of online technologies that facilitate the creation and distribution of content. [Zarella, 2010]. Concise and simple, this definition lays the foundation for a proper understanding of additional facets of social media.

According to Zarella [2010], social media uses many forms:

- blogs,

- micro blogs,

- social networks,

- media sharing sites,

- social bookmarking and voting sites,

- review sites,

- forums,

- virtual worlds

Social Media, however, is not merely additional application to the existing PR or Marketing campaign, nor can be accepted as add-on to the current business model. Fully integrated Social Media can serve as a robust communication platform that with its continues evolution change the current interaction model between company and audience, but also amplify the organisation functionality as a whole. According to McKinsey Global Institute, integration of social technologies within the organisation can create significant value. Based on the research published in Harvard Business Review, the shift from oneto-one communication to one-to-many can improve employees productivity by $25 \%$ [http://blogs.hbr.org/cs/2013/01/look_beyond_a_socia_media_ presence.html 21.01.2013]. 
Figure 2. Overview of the most popular Social Media Platform

\begin{tabular}{|c|c|c|c|}
\hline $\begin{array}{l}\text { Social Media } \\
\text { Platform } \\
\text { Popularity* }\end{array}$ & $\begin{array}{l}\text { Social } \\
\text { Network } \\
\text { Platform }\end{array}$ & Overal Review & $\begin{array}{c}\text { Future Trend* } \\
\text { Where marketers are planing } \\
\text { to increase efforts in } \%\end{array}$ \\
\hline & $\underbrace{15}_{\text {Facebook }}$ & $\begin{array}{l}\text { Integrating over } 600 \text { million people } \\
\text {-features three entities: individual profiles,groups, pages } \\
\text {-additional feature "Like" encouraging broader interactivity } \\
\text {-engaging community through status updates, pictures, videos }\end{array}$ & $\begin{array}{l}\mathbf{6 6} \% \\
\text { growth compare to this } \\
\text { year }\end{array}$ \\
\hline & LinkedIn & $\begin{array}{l}\text { Recruitments, Retantion, Industry Collaboration } \\
\text { - more than } 100 \text { milions users stricly professionals } \\
\text { - greate inside of professionals around the world } \\
\text { - Leverage HR activity and professional connectivity }\end{array}$ & $\begin{array}{l}\mathbf{6 5} \% \\
\text { growth compare to this } \\
\text { year }\end{array}$ \\
\hline & $\begin{array}{l}\text { BLOG } \\
\text { Blogging }\end{array}$ & $\begin{array}{l}\text { Connecting deeply to your target audience } \\
\text { - more than } 100 \text { milions users stricly professionals } \\
\text { - greate inside of professionals around the world } \\
\text { - Leverage HR activity and professional connectivity }\end{array}$ & $\begin{array}{l}\mathbf{6 6} \% \\
\text { growth compare to this } \\
\text { year }\end{array}$ \\
\hline & Twitter & $\begin{array}{l}\text { Rea-time consumer engagmenet } \\
\text {-sharing through: general updates, replies, direct message } \\
\text {-public way of connecting with audience through } 140 \text { characters } \\
\text {-a way to monitor conversation about brand, promotion, and } \\
\text { listenining to consumers engagement }\end{array}$ & $\begin{array}{l}\mathbf{6 4 \%} \\
\text { growth compare to this } \\
\text { year }\end{array}$ \\
\hline & $\begin{array}{l}\text { You } \\
\text { Yube } \\
\text { Youtube }\end{array}$ & $\begin{array}{l}\text { If a picture's worth a thousand words, how many is } \\
\text { Video worth? } \\
\text {-great method of telling a story recarding brand, product, comopany } \\
\text {-building the organisation presence by reaching the right people } \\
\text { through its own TV channel }\end{array}$ & $\begin{array}{c}\mathbf{6 9 \%} \\
\text { growth compare to this } \\
\text { year }\end{array}$ \\
\hline
\end{tabular}

Source: based on information in Dave Kerpen Likeable, David Meerman Scott The New Rules of Marketing \& $P R$

*based on 2013 Social Media Industry Report - May 2013

New ways of communication and sharing content over the web is emphasised in every aforementioned definition. Looking closer into this aspects, Brian Solis examine this phenomena in details, differentiating communication tunnels into three different channels [Branchard 2011 pp. 8-11]:

- Vertical Engagement (one-direction), broadly explored and practiced by company prior 1995, the eve of Social Media. This would mainly represent the 'Old Rules of PR' where organisation crafted message and broadcasted to the audience. Audience didn't have an effective way to communicate back to organisation

- Vertical Engagement (two-direction), embarked in the transition to Web 2.0, with a birth of social networking. Audience is becoming empowered with a possibility of new channels to communicate back to Organisation, they had been given a voice 
- Lateral Engagement (worth of mouth), that is followed by significant change in the social network, by adding additional features into existing platforms (facebook 'Like') and connectivity between various different tools like blog, twitter, location-based applications - influence and trust in lateral communication is earned, not bought.

Figure 3. Communication channel: Lateral vs Vertical forces
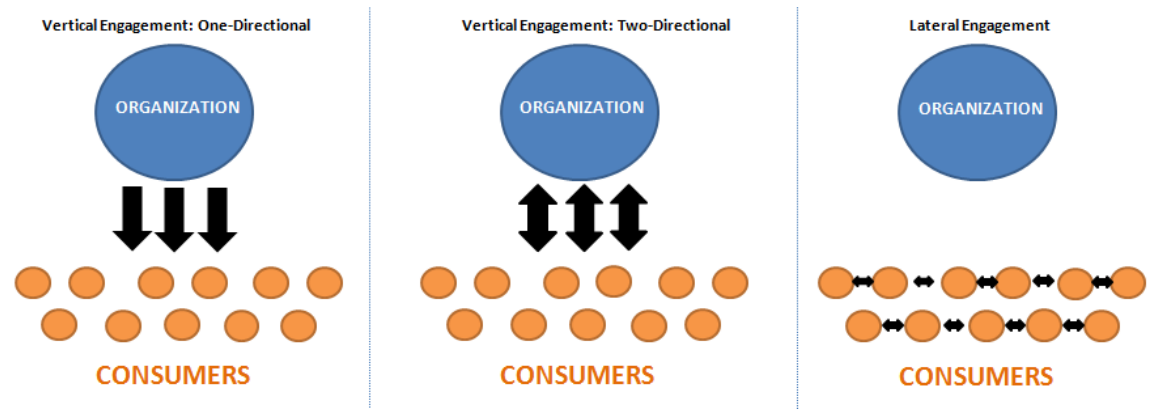

Based on Oliver Branchard Social Media ROI Person Education ltd, 2011 page 8-11

The ability to influence the network based on your own subjective opinion creates the strong power of human engagement. This leverage the audience position in correlation with any organisation, regardless of their market value or geographical presence. This phenomena is broadly embedded within SNS (social networking site) acronym. This phrase is used to describe any Web site that enables users to create public profiles online and form relationships with other users through the internet by interaction with his profile. SNSs have different rules for establishing connections, but they often allow users to view the connections of a confirmed user link and even suggest further contact through the personally established network. Some social networking websites like LinkedIn are used for building professional connections, while sites like Facebook straddle the line between private and professional link and by use of specific algorithm formula that distil and filter incoming feeds through the web [Kerpen 2011 p. 42].

Social Media can be also broadly explained as an important element in the nowadays organisation. This evolution provided the new view on certain element of the organisation, that looking through the prism of dot.com era we can see the great influence on particular elements of the business function. Blanchard articulates five main are where Social Media can enhanced its functionality, additionally to aforementioned PR and marketing [Branchard 2011, pp.18-27; http://www.socialmediaexaminer.com/ 
SocialMediaMarketingIndustryReport2013.pdf 01.06.2013] :

- Sales - mainly by acquiring new customers through its reach and influence according to 2013 Social Media Marketing Industry Report, 62\% marketers confirmed that integration of Social Media improved the sales

- Customer Support - the power to respond to customer in real time and building community of fans - according to 2013 Social Media Marketing Industry Report, $63 \%$ marketers found Social Media useful in developing loyal fans

- Human Resources - a broader choice of recruiting talented individuals according to 2013 Social Media Marketing Industry Report, 92\% found it useful to use LinkedIn

- Business Intelligence - easier, cheaper and faster and richer way of monitoring the web presence - according to 2013 Social Media Marketing Industry Report, 69\% marketers use Social Media to gain marketplace intelligence

The heart of every enterprise is client, which empowered with a new communication medium, consciously exploring the new electronic channels to enhance his own experience towards specific brand or garner knowledge of the product of its own interest. Social media plays vital role in building dual channel communication between enterprise and client. Therefore, understanding the medium by the company is foremost paramount not only in order to gain quantifiable business profit in a long term perspective, but also to be able to effectively plan, measure and manage the whole engagement process. Therefore the ability to control the new medium as an integrated part of the company's structure have found its own point of tangency with CRM concept

With a growing tendency in the search for a definition and classification of new concept CRM 2.0 or less enigmatically Social CRM, we can experience visible debate around this topic, emerging mainly in U.S.A. One of its precursors, Paul Greenberg, urge that old CRM definition needs to encompass new medium with respect to new communication pattern, customer's expectation or empowerment and needs to change company's old perception towards new digital landscape. Therefore, he articulates in the new SCRM definition, importance of forging collaborative conversation with customers that will provide ultimate mutual value that emerge on trusted and transparent business environment [Greenberg 2010, pp.34-35].Unlike the old CRM approach, that mainly focus on internal operational management level towards customers' relationship measurement, in SCRM focus shift towards more customer orientated sphere, where the main company's objective needs to meet the customers agenda and customer engagement with the company. This is area where we see companies adopting CRM technology with new business intelligence concept, where one 
of the prime function is to concentrate on monitoring their web presence and act accordingly to the specific circumstances. Additional electronic channel is great source of the customers feedback that can be used as an integral part of the customer service strategy, where the diversion of the channel from the traditional bricks-and-mortar presence to dot.com environment can be effectively monitored and further resolved, building new engagement model between customer and company.

\section{Research methods and findings}

Understanding the broad aspect of Social Media we need to explore this topic further and look at the practical expertise based on the company's presence in the real world. Through the further examination by exploring the presence and activity on few organisation established in both UK and Polish market, the author would like to elaborate the conclusion based on the following case studies. Although, these companies may be interconnected through existence of the market sector structure, operating in similar landscape of the business, they unique approach and understanding of the topic distinctively differ from each other.

Social Media is slowly becoming as an indispensible tool in the company's armoury. According to AICPA (American Instiute of CPAs), social commerce sales totalled $\$ 9.2$ billion by the end of 2012, and there is strong evidence that will reach $€ 14.25$ billion by end of 2013 [Macarthy 2013, p. 4-5]. We see strong engagement of companies of introducing and integrating social media techniques and tolls to leverage their business model, that based on this figures in North America should expand by over 50\%. Can we see similar pattern on old continent, Europe?

\section{Case Study 1 -UK Automotive Aftermarket industries - Aftermarket Distributor}

Author reviewed and examine closer presence of one of the biggest on UK aftermarket sector car park distributer. Company successfully operating in the brick-and-mortar environment successfully straightening their presence nationwide by rapid expansion of the branch network. With over 140 location nationwide company covers almost $92 \%$ of the UK region. This strong presence in the sector together with effective organisational and functional structure build their reputation as a leader in the industry.

Reviewing closer their operational element in the market sector, we can broadly view their potential strength mainly based on the robust and effective physical distribution channel, that supports the national network in the product availability level and communication channel that serve as an additional improvements in $\mathrm{B} 2 \mathrm{C}$ and $\mathrm{B} 2 \mathrm{~B}$ structure. Understanding importance of the 
new trend on the market, company continuously looking for new opportunities to explore the new digital technologies in leveraging their operational level and brand position on the market.

It's strongly emphasised throughout different functional level of the organisation, that ongoing efforts cannot be achieved without further improvement that will be solely based on the digital technology. This has been seen as the main objective in the following area:

- E-commerce External - Sales - building strong position on the market to support traditional distribution channel. It serves as effective tool in driving sales-leads towards website presence or alternatively to physical branch location. Integrated within the existing organisational structure serve as a strong vehicle in supporting the business objective. The electronic channel generates over 70,000 views every day and is considered as a powerful tool in accomplishing the ultimate goal - company's growth.

- E-commerce Internal - company see the strong influence of industry standards to improve the existing communication level within its own and between partnership organisations. It is broadly seen by integrating main peripheral operational system into one MIS platform. This provide the robust system of effective way of distributing and sharing companies marketing internal martial, reports, and analytical data including CRM and HR files. As an external to ERP system, is directly interconnected with main data server that serving as main repository, enables all key suppliers to communicate and exchange information data in the live presence.

E-commerce is strongly embedded in the company business function, however, Social Media should mainly serve as a new external communication model . Reviewing this aspect closer within the company, we can see that the utilisation of the program is more visible internal within the organisation, rather than external factor that would drive PR and marketing activity and adhering to the new trend. The main reason for that operational distinction can be sourced in Social Media ROI and metrics used to analyse important KPI or simple effectiveness of this channel. Let's look into that closer:

- Internal Organisational Function - one of the main objective is to improve the communication effectiveness within the organisation. Therefore company will be re-building the existing channel with replacing it with one-to-many platform, supported by IM system with live presence mode that will be build on existing MIS architecture. Frequently use of Webinars and Prodcast as an additional channel to convey important message. This is solely to improve the operational level within the company and connectivity between different organisational functions divisions. Which is easy to monitor and capture, by using the benchmark matrix 
- External PR \& Marketing - company have visible and active presence on facebook, youtoob and their own website, which they sole function is to support sales activity both on electronic \& traditional channel. It understands importance of communicating with customers that appears on company's website, however, is only limited to the their own web page or on-line profile. There is strong Extensively exploring Social Media outside of the organisation will be difficult to measure from the effectiveness point of view and there are no current supporting evidences on the market that it would require to broaden company exposure on electronic channel.

Reinforced by the strong presence in the brick-and-mortar channel, company understands the changing environment that they need to operate in. They solid fundament on traditional operational level, however, provide them evidence to support the current model, rather than re-directing their efforts and solely exploring new way of communicating with the audience. Management strongly believe that traditional PR strategy, provides solid fundament to build adequate brand recognition and effective communication model with the audience. Any possible consideration of changing status quo would have to be mainly triggered by the transparent change in current market standards and landscape.

\section{Case Study 2 -UK Automotive Aftermarket industries - Suspension component Manufacturer}

Well positioned global brand, with 50 years heritage on the market, build their close partnership with main distributors around the word. It offers comprehensive product portfolio in suspension program, in both direct o.e. equivalent replacement and performance product category. It is known on the market by supporting for example NASCAR, where almost $90 \%$ of the vehicles are equipped with their products. Company is fully aware that being a global brand operating in the midst of the changing environment can make them more vulnerable in some sectors and become challenging to operate in others at the same time. Their operational presence on UK market, even considering the global brand recognition, was very unstable. Therefore, they have recently decided to change the distribution model, from the business partnership with local retailers that they had to strongly relay on, to direct distribution. Company re-enter the market by building their own presence through the investment of their own logistic infrastructure. This new more centre-controlled model, however, required building effective PR and marketing campaign to re-store their presence on the market and more importantly focus on customers to alter their brand perception to a solid local partner. Therefore, is not surprisingly, that mainly due to the very overall operational cost of launching the program, which directly limited expenditure budget on PR and marketing, organisation decided to use Social Media as the main and ultimate communication channel. 
Their main strategy was to engage in every dialog triggered in the internet that would relate to their prime product. Concentrating on the forums blogs, or even twitter, they can actively monitor the company brand growth, public presence and listening to the audience by offering continues and complex support and advice. By using web monitoring systems like Radian6,or even free to download equivalent Technorati blog search, it offers instant and comprehensive toll to measure and engage with the client across the entire social Web. Company's main goals is to target specific clients group, structured by their closer analysis and understanding of the customer behaviour. It has been so far considered one of the most important tool in performing the PR and marketing activity. Firstly because of its resource requirements for program, that can be driven and controlled by even one person, but also comprehensive and effective PR toll that enable performing in-details search through the entire internet platform in exploring customers' needs to communicate with them adequately to their expectation.

The main company's objective is to broaden and strengthen their activity on the market through the further expansion and utilisation of the Social Media channel. The management understand the complexity and importance of being active in electronic presence, cultivating the principle of "maximum information for minimum cost".

\section{Case Study 3. Polish Automotive Aftermarket industries - Aftermarket Distributor}

The emerging paradigm shift in the customer's service has been acknowledged by one of the biggest automotive aftermarket parts distributor on polish market. The company is offering replacement products and accessories to passengers and commercial cars. With its broad product portfolio, company supports DIY (Do it Yourself) sector and national repair centres, where understanding of the customers connection with the product and brand is important especially considering nature of the sector where the technology and component complexity is continuously evolving. Company has been recognised by the respected in the industries rankings published by the Money.pl and Gazeta Wyborcza as one of the leaders in the market. Their visible presence in dot.com has been also highly recognised as one of the most popular players in the industry, according Internet Standard and results of Gemius research. Their active engagement with all stakeholders on Facebook and Google+ resulted in building a large group of fans. Growing reputation of the company, was partly based on the closer utilisation of the international aftermarket parts catalogue software TecDoc, which with a daily information update system, offers solid framework in building own product catalogue application for the customers. 
Company use social media to monitor customers activity as a part of the daily routine process framed within CRM strategy. This valuable source of information is archived in central data base, which that can serve as a general repository for all related operational departments. The process of monitoring the web presence creates an operational fundament for the company to understand the evolving characteristic of its customer and preparation for next marketing or PR campaigns. Social media also offers as a new sales channel, where effectively managed offers vast amount of promotions that that can attract customer and creates additional sales leads. Considering the large number of fans on Facebook each offer can broader the audience target by potential new customers, encouraged by their friends generating subsequent online post. There are also tangible benefits for fans like, $4 \%$ discount on the purchase or free delivery on the next on-line order.

\section{Case Study 4. Polish Automotive Industries - Car Manufacturer}

In the automotive industry, not only aftermarket sector see a growing potential in the Social Media and new communication channel. There is prevailing understanding and visible integration of the new medium also by the car manufacture, which especially in the highly competitive market understanding the customer's expectations is more important than before. It is paramount, however, to identify the right medium that can provide sufficient and most effective platform to communicate with audience. It is not surprisingly why Internet forum is one of the most popular places where customers gather together to share and garner information about specific vehicle, new features or even technical tips. Based on the released research in Social Press, over $94 \%$ [http://socialpress.pl/2013/06/znaczenie-forow-internetowych-w-branzymotoryzacyjnej/\# ]of respondents acknowledged that forums are one the most favourable platform by the customers. According the same research, that internet forums have immense impact on those vehicle models, that are highly influenced by ROPA effect (Research Online Purchase Offline), which is the customer's tendency to utilised internet as a medium in order to obtain viable information about the specific model of the vehicle before the final purchase. According to the same research, over $70 \%$ of the vehicles sold in Poland was subject to ROPA effect.

There are numerous forums available on the internet that are widely open for any new visitors. This transparency of the forum offers not only a great place to source a specific information about the particular topic pertaining to a specific vehicle model, but also effective platform to share subjective experience between those car users. One of the global car manufacture, offers forums as a great place to gather current or potential users to talk about their own experience from driving of the vehicle or even maintaining the car. 
Professionally developed platform can be beneficial for all involved parties gather around the coherent topic, few examples:

- Potential Customer - relevant information about specific model, offered not in the form of marketing bulletin, but as a shared experience of the users and owners of the same vehicle.

- Current Users - provides a great source of shared experience and knowledge in day-to-day car maintains, repair tips, car parts or even technical support

- Car manufacturer - as a viable source of information on the current model and further R\&D, customer characteristic and potential new market trends

- Manufacture Franchise Distributer - as a place to offer information regarding specific offer test drive or details of the vehicle option in store Forum, as an effective channel, offers a great opportunity to meet your customer and understanding them better as a ordinary vehicle driver. Comprehensive monitoring activity and involvement in the communication between the users, company may offers its own professional support and what is also important, be alerted on specific topic that can potentially damage the reputation before the further escalation of the problem. As a source of information, Social Media offers viable feedback that can be used in crafting new marketing promotion or PR strategy that based on that mutual expertise can ultimately serve as a great channel of enhancing the company's position and presence on both internet and traditional market environment.

\section{Limitation}

This study covers a broad range of topics including PR and social media. It was therefore necessary to give just a general insight into each of these areas. This article does not cover the whole range of activities performed by managers and specialists from PR departments in organizations nor does it analyze the outsourcing of these activities. Social media was introduced although its broader uses and implications were not further examined.

\section{Summary}

On the one hand social media made PR more open and democratic on the other leaves open door for unethical practices. The good news is, any company that want to establish their presence through social media, needs to be transparent and authentic. Otherwise any unethical activity may undermine their presence rather than build artificial brand position. The research shows using this method alone that becoming more Social friendly it's first of all understanding the complexity of this topic and effective integration within the existing structure. Both UK and Polish market examples shows distinctively different approach to Social Media as a new concept. From one side we see strongly established entity on the traditional market that solely rely on the bricks-and-mortar presence, understanding new technologies but with 
acceptable hesitation. As an entity that focus on capturing theses elements of Social Media that is easier to monitor and gauge, shifting the organisational objective to focus on elements that mainly leverage the internal operational level of the company. And from the other hand, global brand that entering the market actively encompassing Social Media in their PR strategy to build brand position, listening to dialogue and actively engaging in communication to enhance their local and global presence. One of the most difficult aspects in any revolutionary and disruptive innovations, is changing the current status quo by company's adaption and adherence to the new prevailing model. It could be, therefore, considered as a difficult for one organisation cultivating strong, traditional business culture and old PR rules to comprehend the new paradigm shift, where it may requires time to understand the potential of Social Media before their fully embark the web presence. But even global companies, entering the new geographical market, realising the complexity of the topic and importance of integration of their operational CRM with Social Media to support PR strategy. The real question now is not if those considered traditional entities adapt the presence to the new model, but when, and whether it will not be too late before the whole market structure move towards a new, virtual word-of-mouth, leaving old players behind the new Social connection.

\section{Bibliography}

Andrew Macarthy 500 Social Media Marketing Tips , Fall Edition, 2013

Chris Anderson The Long Tail, Random House Business Books, 2009

Grandys E., Grandys A., Transnational corporations and cross cultural management, OiK, Nr 5 (148), 2011

Dave Kerpen Likable Social Media McGrave Hill 2011

David Meerman Scott The New Rules of Marketing \&PR, Third Edition, John Willey \& Sons, 2011

Oliver Branchard Social Media ROI Person Education ltd, 2011

Paul Greenberg CRM at the speed of light - Social CRM strategy, IV edition Mc Graw Hill, 2010

Sułkowski, Ł.,The problems of epistemology of corporate culture, Journal of Intercultural Management, Vol. 1, No. 1, April 2009,

http://www.socialmediaexaminer.com/SocialMediaMarketingIndustryReport2013. pdf 01.06.2013

http://blogs.hbr.org/cs/2013/01/look_beyond_a_socia_media_presence.html 21.01.2013

http://www.prsa.org/aboutprsa/publicrelationsdefined/ 30.07 .2012

http://socialpress.pl/2013/06/znaczenie-forow-internetowych-w-branzymotoryzacyjnej/\# 25.06.2013 